\title{
An analysis of the relative importance of biotic and abiotic factors to the niche of the cockroach genus Arenivaga (Rehn) (Blattodea: Corydiidae) ${ }^{1}$
}

\author{
Heidi Hopkins ${ }^{2}$ and J. Tomasz Giermakowski ${ }^{3}$
}

\begin{abstract}
Arenivaga occur across the American Southwest and Mexico, as well as in the scrub and high pine communities of Florida. This study analyzes the relative contribution of 22 abiotic and one biotic variable to the niche of the genus Arenivaga. This analysis revealed that more than $95 \%$ of their ecological niche is described by eight variables: soil, isothermality, minimum temperature of the coldest month, mean temperature of the driest quarter, annual precipitation, precipitation of the driest month, precipitation of the wettest quarter and ground cover. These eight variables with respect to their relative contributions to the niche of the genus as a whole as well as the individual niches of 27 species in the genus were then examined. This revealed the similarity of niche composition of most of the species, as well as how varied the niches were of several species. A species dendrogram built from similarity of contribution of the eight variables to niche composition was compared to a phylogeny of the genus, but few similarities in topology were found. This analysis revealed that soil is the most important contributor to these species' niches, followed by precipitation of the driest month, and finally, precipitation of the wettest quarter. It also confirmed that the majority of Arenivaga species have niches comprised of similar, but not identical, proportions of as few as four, and as many as eight ecological variables. Currently there is no evidence to support niche conservatism between closely related species, indicating that adapting to new and variable niches is one of the drivers of speciation in this genus.
\end{abstract}

Key Words: Arenivaga. Blattodea, cockroach, Corydiidae, Polyphagidae, ecological niche models, niche conservatism, niche evolution, species boundaries, species distributions.

\section{Introduction}

A point of great interest to biologists, especially in this time of global

\footnotetext{
${ }^{1}$ Received on September 1, 2014. Accepted on September 16, 2014. Last revisions received on October 6, 2014.

2 Department of Biology, 1 University of New Mexico, MSC03 2020, Albuquerque, New Mexico 87131 USA. Email: cockroachdoc@gmail.com

${ }^{3}$ Museum of Southwestern Biology, MSC03 2020, 1 University of New Mexico, MSC03 2020, Albuquerque, New Mexico 87131 USA. E-mail: tomas@unm.edu
}

DOI: 10.9784/LEB2(3)Hopkins.01

Electronically available on October 17, 2014. Mailed on October 17, 2014. 
climate change, is species distribution patterns. When considering the presence or absence of a taxon in a given terrain, as well as its abundance if present, questions arise as to what factors contribute to the success or failure of that taxon in the environment. Species' distributions are constrained by a variety of environmental factors both biotic and abiotic, such as temperature, precipitation, ground cover, food resources, and predation, which factors comprise the niche of that species. A species cannot persist in an area in which its basic requirements for survival are not met. Those requirements include, for example: sufficient territory to acquire essential nutrients and mates; terrain that is unfavorable to predators or permits escape from predation if one is a prey item, or the opposite if one is a predator; and sufficient niche diversification to prevent competition from congeneric species (Lomolino et al., 2005). In addition, the distribution and survival of a species across a given terrain, as well as the radiation of that species into two or more daughter lineages (adaptive speciation), is profoundly affected by adaptability to new ecological variables, geographic disruption, and isolation caused by stochastic vicariant events (Figure 1) (Coope, 1994; Lomolino et al., 2005; Araujo and Luoto, 2007). A taxon's ability to adapt to changes in the environment determine that taxon's presence and density in the landscape, its persistence in the environment over time, and its acquisition of adjacent territory through migration, expansion, or speciation (Gaston, 1998; Peterson, 2003). Much of this can be summarized as a tendency towards niche conservatism (the tendency of a species to retain its ancestral traits, resulting in closely related species occupying similar ecological niches), or niche evolution (the opposite tendency from niche conservatism, in which a species proves remarkably adaptive to varying ecological niches), in a species (Wiens and Graham, 2005; Smith et al., 2005; Wiens and Donoghue, 2004). This paper examines the relative contributions of biotic and abiotic variables to the niches of the genus Arenivaga, as well as to the niches of 27 species within the genus.

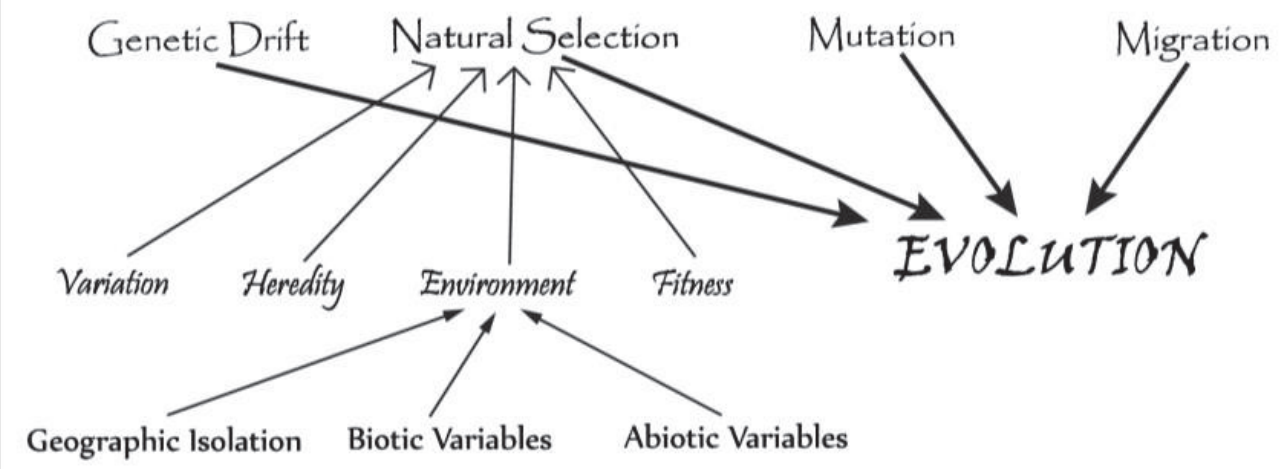

Figure 1. A diagram of the factors that contribute to evolution. 
One way to begin to understand the environmental factors that account for the pattern in which species are distributed is to map a species' distribution and then search for biotic and abiotic factors that unite the resulting range. This process, known as ecological niche modeling (ENM), is complicated by limited knowledge of the factors critical to a given species' success. For example, climate data for a species' habitat is readily available, but a measure of the contribution to a species' niche made by a facilitating symbiont, or understanding the impact of a taxon's vagility upon its niche may be much more difficult. Consequently, these latter variables are rarely if ever included in ecological niche modeling; therefore, all conclusions of such modeling must be understood within the limited context within which they are drawn. In addition, environmental factors play a role in both permitting and preventing the successful occupation of an area by a species (Stevenson, 1982; Krasnov and Shenbrot, 1996). Therefore, the factors contributing to species' realized niches are complex and varied, but not outside the abilities of science to discover.

Ecological niche models permit enumeration and quantification of the factors that are determinants of a species' presence in the landscape (Elith et al., 2006; 2010, Wiens and Graham, 2005). They also can be used to predict whether a species is likely to be present in an unsampled area, or predict where a species may successfully migrate as a result of climate change or other anthropogenic changes to the environment. Whereas many models created to predict species' ranges have been based on abiotic variables, Gonzalez-Salazar et al. (2013) showed that inclusion of biotic variables could result in higher predictability (although also see Meier et al., 2010); therefore both types of variables were used in this study.

This study examines the relative importance of 23 biotic and abiotic factors in determining the ecological niche of the cockroach genus Arenivaga, and the niches of 27 species within that genus. It seeks to answer the following questions: Which biotic and abiotic factors are strongly predictive of where Arenivaga may be found? What are the relative contributions of those factors to the ecological niche of the genus? Are these factors mirrored in their relative importance amongst 27 species in the genus and can any species be grouped according to similar biotic or abiotic niche requirements? Finally, are there any correlations between habitat requirements and evolutionary relationships in the genus that allow us to conclude that the species of this genus tend towards niche conservatism or niche evolution? (Peterson, 2003; Wiens and Graham, 2005; Wiens and Donoghue, 2004).

\section{Methods}

Study Subject. Arenivaga is a subterranean genus of cockroaches in the family Corydiidae (Polyphagidae, sensu lato) that are found in the American Southwest, Florida and Mexico. Corydiids are found in desert regions of the world and are united by their characteristic hairy, spined appearance and by 
almost universal sexual dimorphism, in which the males are gracile and winged and the females robust and apterous. Additionally, they have cercal tricholiths, pendulous structures on the ventral surface of the cerci that move in response to gravity and provide attitudinal orientation for the animal (Walthall and Hartman, 1981; Hartman et al., 1987). Females and nymphs live a subterranean life in sandy, dune habitats, rocky terrain, and drier scrub and wooded habitats, feeding on mycorrhizal fungi, leaf detritus of desert shrubs, pollen, and the seeds collected by the mammals whose burrows they cohabit (Cohen and Cohen, 1976, Hopkins, personal observation). A minority of species can be found in other terrains that receive greater precipitation, calling into question their common designation as "sand" or "desert" roaches (Figure 2). Their cryptic life history has never been fully documented although some of their remarkable physiological adaptations for life in the desert, such as their ability to obtain moisture directly from the air and their unique antennal chemoreceptors, are well-studied (Cohen and Cohen, 1981; Edney, 1968; Edney et al., 1974; 1978; Edney and McFarlane, 1974; Hawke and Farley, 1971a; 1971b; Jackson, 1983; O'Donnell, 1977; 1981; 1982). Mature males, the only winged form, live most of their short lives above-ground (Appel et al., 1983). Females are most active near and at the surface during the summer, which is most likely the mating season. Mature females "swim" to the surface after dark when the first few centimeters of sand have cooled. There they wander the surface of the sand, presumable attracting males using pheromones (Hawke and Farley, 1973). Courtship has never been described, but mating proceeds in the typical end-toend manner of Blattodea (Hopkins, personal observation). The dorsal habitus of the 27 species included in this study are shown in Figures 3-4.

Species occurrence data. This analysis is based on locality data of more than 5200 adult male specimens of Arenivaga. These specimens better represent areas of the United States than Mexico. Although Mexico includes a great diversity of Arenivaga it is under-collected for this genus. One exception is the Baja Peninsula, which is better surveyed for many arthropods, including Blattodea (D. Lightfoot, personal communication, Lightfoot and Weissman, 1991; Lightfoot, et al., 2011; Weissman et al., 1980; Vickery, 1997; Kevan, 1990; Gomez et al., 2012). A list of institutions from which specimens examined for this study were borrowed can be found in Hopkins, 2014. Additional specimens were collected in the field by Hopkins. 


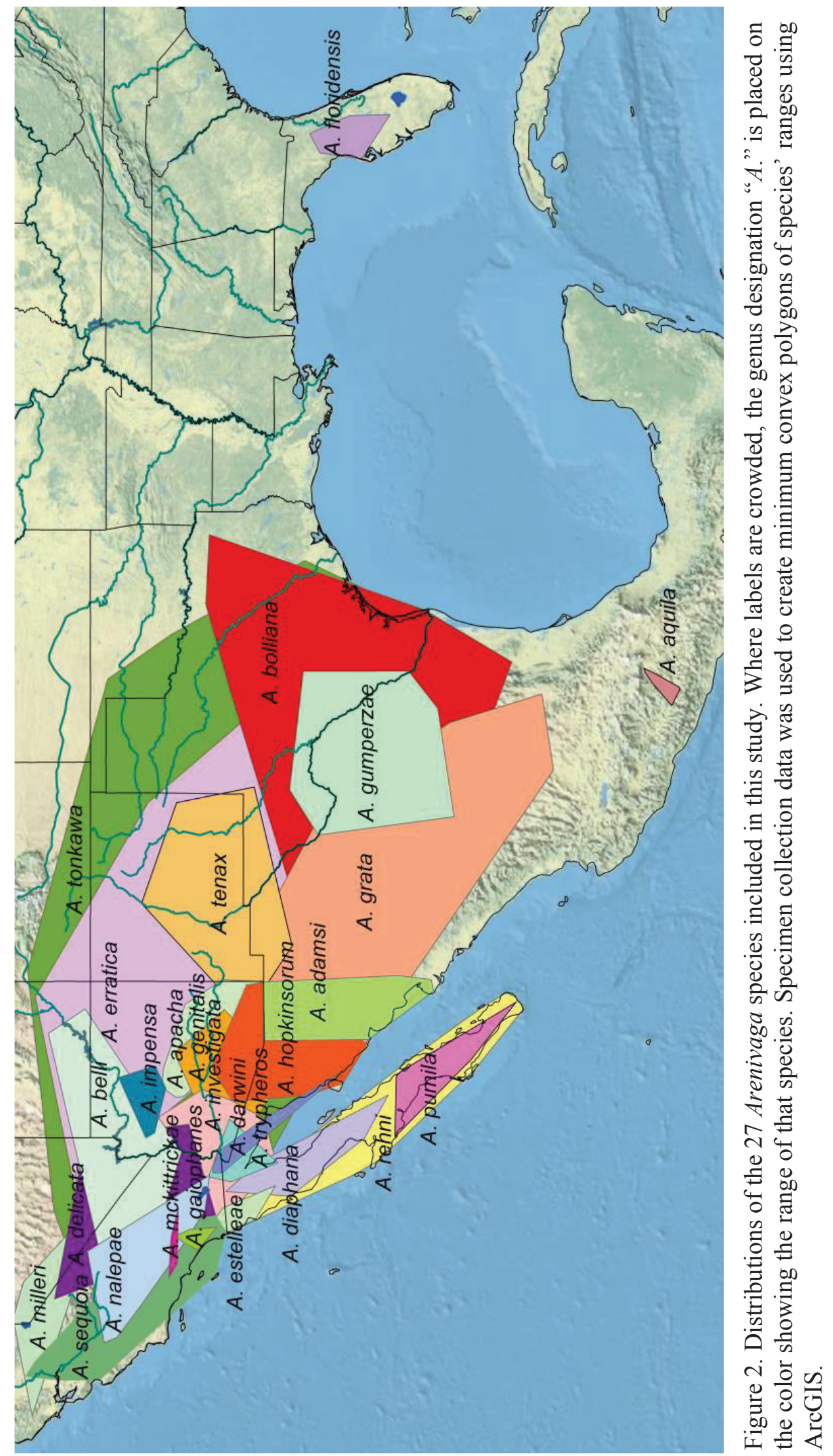



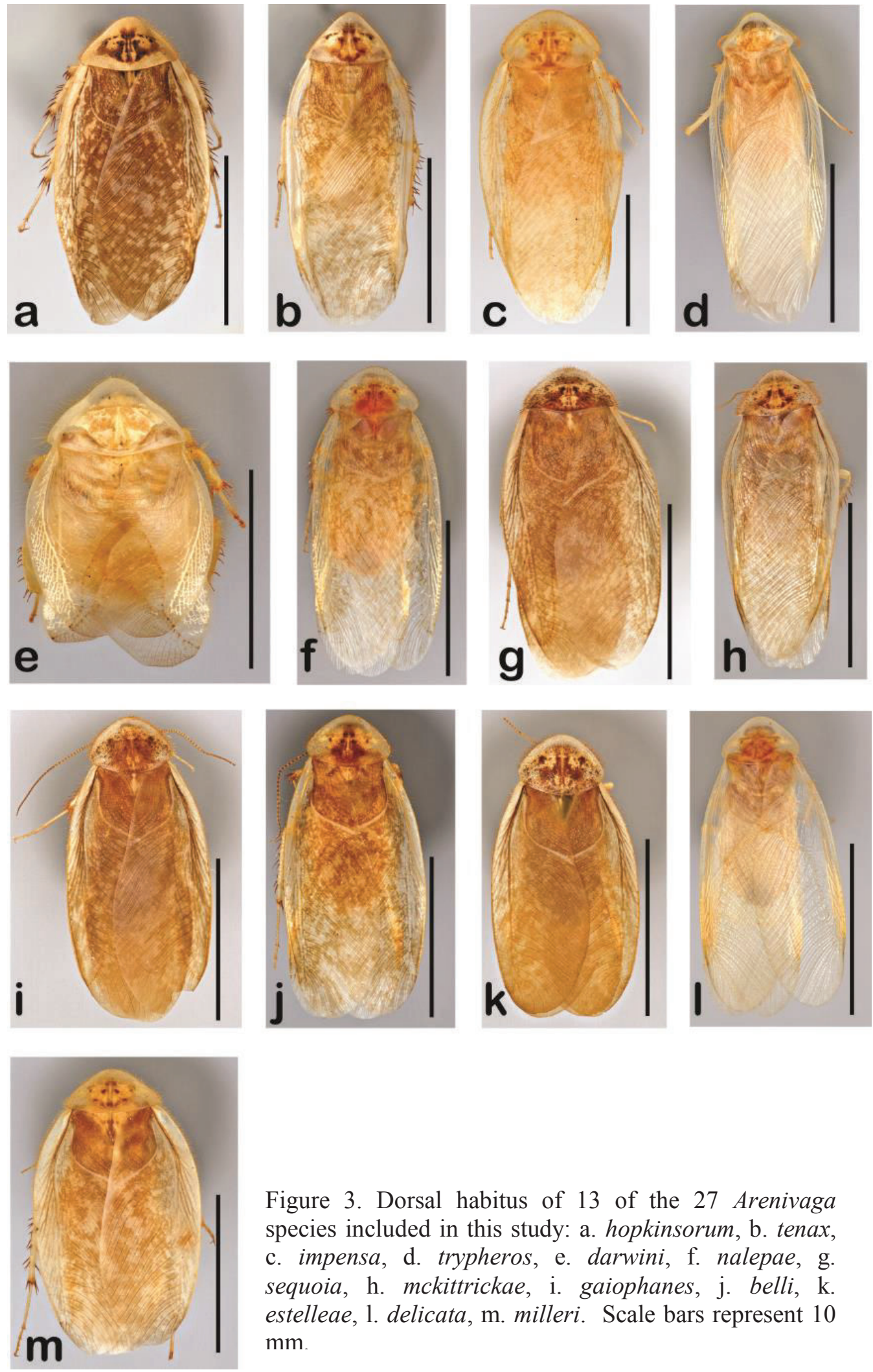

Figure 3. Dorsal habitus of 13 of the 27 Arenivaga species included in this study: a. hopkinsorum, b. tenax, c. impensa, d. trypheros, e. darwini, f. nalepae, g. sequoia, h. mckittrickae, i. gaiophanes, j. belli, k. estelleae, 1. delicata, m. milleri. Scale bars represent 10 $\mathrm{mm}$. 

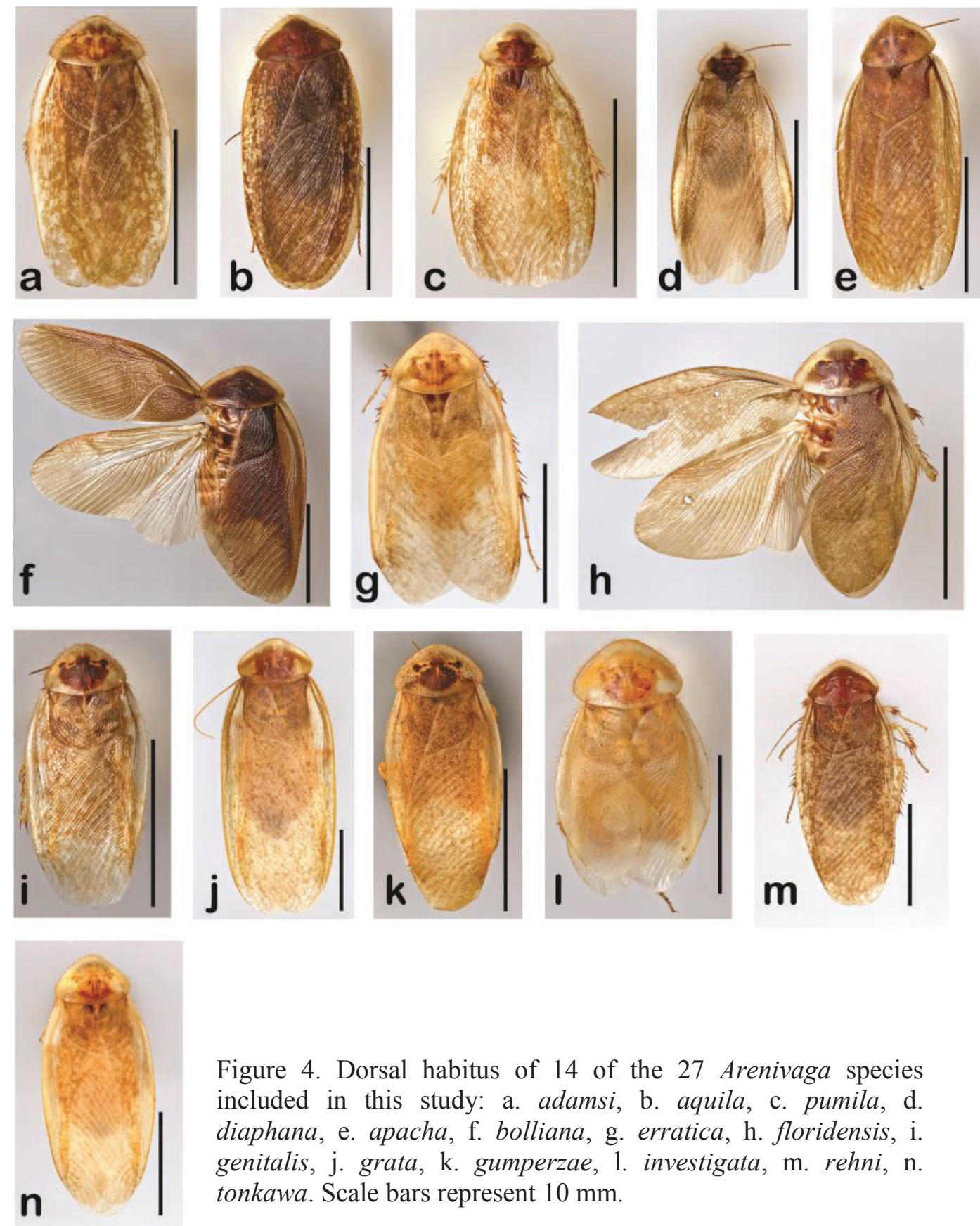

Figure 4. Dorsal habitus of 14 of the 27 Arenivaga species included in this study: a. adamsi, b. aquila, c. pumila, d. diaphana, e. apacha, f. bolliana, g. erratica, h. floridensis, i. genitalis, j. grata, k. gumperzae, 1. investigata, m. rehni, n. tonkawa. Scale bars represent $10 \mathrm{~mm}$.

All distribution information is based on males (the wingless females and immatures cannot be identified to species based on morphology, Hopkins, pers. obs.). Only rarely were latitude and longitude provided on specimen data labels, thus each locality without these data was georeferenced using Google Earth. Coordinates were then entered into ArcGIS 10, and distribution maps produced. The maps were used to clean the data by inspecting them for outliers that might indicate potentially problematic georeferences or label data, and such specimens 
were eliminated if significant doubts about the locality remained. Although there are 48 species of Arenivaga, only 27 with more than five distinct locality records were used in order to ameliorate the effects of small sample size on the significance of the results. A bootstrap analysis was done (Peterson and Cohoon, 1999) to determine whether there was an adverse effect on the analyses from small sample sizes of some of the included species.

Environmental Data. The data for some abiotic variables pertinent to this study were accessed through WorldClim's collection of 19 temperature and precipitation variables available from their BioClim website (http://worldclim.org/bioclim) (Hijmans et al., 2005; Busby, 1991). These 19 variables represent measures taken annually and seasonally, as well as the extremes of temperature and precipitation. In addition, the soil data from the Harmonized World Soil Database (HWSD) (Nachtergaele et al., 2012) were used. This database, created under the auspices of the Food and Agriculture Organization of the United Nations (FAO) and the International Institute for Applied Systems Analysis (IIASA), combines four world soil databases to create the most complete picture of soil types of the entire planet. A measure of terrain ruggedness was generated by applying a script that quantifies the topographic texture of terrain by combining measures of variability in slope and aspect (Vector Ruggedness Measure or VRM, Hobson, 1972; Sappington et al., 2007). This analysis also used a measure of altitude (digital elevation model or DEM) as well as data on major vegetation types from the Global Land Cover 2000 (GLC2000) database (Latifovic et al, 2003; 2004). See Table 1 for a complete listing of variables. All variables were processed in ArcGIS 10.1 (ESRI Inc., Redlands, CA, USA) at a common scale of 30" (approximately $1 \mathrm{~km}$ ); the distribution of all species studied extends over more than $50 \mathrm{~km}$ and therefore would not be influenced by the 30 " scale. Although this scale could be problematic for fine scale analyses of microhabitat selection, it is the most comprehensive and consistent data available for the range of Arenivaga.

Modeling Procedures. Because there is little knowledge about the distribution of the genus Arenivaga, all available presence localities were analyzed for the entire genus using 23 biotic and abiotic variables. From this initial analysis, only the eight variables that contributed a total of more than $95.24 \%$ of the niche of the genus were retained. Further analyses examining the niche of each species were based on those selected variables.

The extent of distribution was modeled using the Maxent algorithm (version 3.3.3k, http://www.cs.princeton.edu/ schapire/maxent/; Phillips et al., 2006; Phillips and Dudík, 2008). Maxent uses a maximum entropy probability distribution to contrast occurrence data with environmental data in the background and estimates a probability distribution that has the maximum entropy (i.e., that is most spread out, or uniform) given certain constraints. The constraints are that the expected values of each feature (for example, a variable representing annual precipitation) must equal the empirical average (the average 
value at known occurrence points; Phillips et al., 2006). Maxent is one of the best algorithms to calculate the suitability of landscape for a taxon when presence/absence data are not available (Elith et al., 2006; Elith and Leathwick, 2009). Models built with presence-only data do not incorporate information on the frequency of occurrence of a species in a region, and therefore cannot accurately predict probability of presence (Guisan and Thuiller, 2005; MacKenzie et al., 2002). However, such models can be used to estimate a relative index of the suitability of landscape for a species (Elith et al., 2006). Here Maxent was used to evaluate the relative contribution of variables rather than make predictions.

Models were fitted in Maxent using functions for random seeds, selection of background, cross-validation and model averaging (Phillips and Dudík, 2008). Although choice of background data can have important effects on predictions (VanDerWal et al., 2009), a random set of data was used as pseudo-absences selected from within a set distance from known localities for Arenivaga. The distance was calculated as the average nearest neighbor distance between all known localities (see Species occurrence data above). A large number of locations (1000) from a broad range of conditions were used to ensure good representation of all possible environments, which is important when models are based on different conditions. Models were then generated to estimate errors around fitted functions and evaluate predictive performance on held-out data (Elith et al., 2010) by using ten bootstrapped model runs. In addition, 20\% of cells were selected for model testing, whereas the remaining $80 \%$ were used for model training (to formulate the model parameters).

The importance of different variables was evaluated for inclusion in the final models in several ways. Initially, the analysis incorporated all 23 variables but did not include any variables in models that would account for spatial pattern in the distributional data. To develop models based on current conditions, this study used the default settings in Maxent but restricted model building to hinged, threshold, quadratic and categorical features (in machine learning language, features are transformations of variables into functions). This is because hinge features produce model projections similar to those based on generalized linear or additive models (GLMs or GAMs; Elith et al., 2010; Phillips and Dudík, 2008). Product features were not selected because of the complexity in the ecological interpretation of interacting variables, and linear features were not selected because they tend to be redundant with hinge features (Elith et al., 2010). Default regularization parameters were selected for all models because of lack of data on detectability of different species. All continuous variables were examined for correlations by calculating the Pearson pairwise correlation coefficient for every pairwise combination of files using ENM Tools (Warren et al., 2010). However, correlated variables were not excluded because the strength of correlation varied spatially and because analyses have also shown that Maxent is more stable in face of correlated 
variables than stepwise regression (James et al., 2013). Included predictor variables were assessed using the built-in jackknife tests that, for each variable, quantify its contribution to the model (expressed as percent and based on increase in gain; Phillips et al., 2006) and permutation importance (Phillips and Dudík, 2008).

Models were run excluding variables with less than $3 \%$ contribution differences in area under the curve (AUC) were examined for both training and test data. Area under the curve of the receiver operating characteristic (ROC) was used as a threshold-independent measure of model performance (Elith et al., 2006). The AUC characterizes performance of the model at all possible thresholds and is summarized by a number ranging from 0 to 1 , where 1 indicates perfect model performance, 0.5 indicates the equivalent of a random (presence and background not different), and less than 0.5 indicates performance worse than random (Phillips et al., 2006).

Cluster and ordination analyses. Nonparametric multidimensional scaling analysis was used to portray in two dimensions the impact of the selected eight variables on individual species' distributions and evaluated the overlap of variable importance between species based on this ordination. The $\mathrm{R}$ statistical language version 3.0.2 (R Core Team, 2013) and the R package "ecodist" were used for these analyses (Goslee and Urban, 2007). In addition, based on the relative importance of variables in models, a matrix of similarity between observations was generated and used to ordinate and cluster the observations. A dendrogram of the similarity of variable importances of each species was generated based on a matrix of Mahalanobis distances and the average clustering method. This method uses a linkage function specifying the distance between two clusters and is computed as the average distance between objects from the first cluster and objects from the second cluster. The dendrogram generated was then compared to a phylogeny of the genus to see if any similarity of topology and clade structure were revealed between habitat requirements and evolutionary relationships.

\footnotetext{
Results

Exploratory Analysis -- Which ecological variables contribute to the ecological niche of the genus Arenivaga? The exploratory analysis revealed that of the 23 ecological variables examined, only eight contributed significantly to the niche of the genus Arenivaga: isothermality (the measure of the day-tonight temperature difference as compared to the summer-to-winter difference), minimum temperature of the coldest month, mean temperature of the driest quarter, annual precipitation, precipitation of the driest month, precipitation of the wettest quarter, ground cover, and soil type (Table 1).
} 
Table 1. Percentage contribution of 23 environmental variables to the ecological niche of the genus Arenivaga. The eight variables in bold describe $95.24 \%$ of the niche and only these variables were used in the remainder of the study.

\begin{tabular}{|l|c|}
\hline Variable & $\begin{array}{c}\text { Percent contribution to ecological } \\
\text { niche model of the genus }\end{array}$ \\
\hline Ground Cover & $\mathbf{3 . 6 1}$ \\
\hline Soil & $\mathbf{9 . 4 7}$ \\
\hline Altitude & 0.28 \\
\hline Vector Ruggedness Measure & 0.32 \\
\hline Annual Mean Temperature & 0.00 \\
\hline Mean Diurnal Range & 0.16 \\
\hline Isothermality & $\mathbf{3 . 8 1}$ \\
\hline Temperature Seasonality & 0.00 \\
\hline Maximum Temperature of the Warmest Month & 0.04 \\
\hline Minimum Temperature of the Coldest Month & $\mathbf{1 1 . 7 2}$ \\
\hline Temperature Annual Range & 0.20 \\
\hline Mean Temperature of the Wettest Quarter & 0.07 \\
\hline Mean Temperature of the Driest Quarter & $\mathbf{1 8 . 8 4}$ \\
\hline Mean Temperature of the Warmest Quarter & 0.00 \\
\hline Mean Temperature of the Coldest Quarter & 0.04 \\
\hline Annual Precipitation & $\mathbf{2 2 . 8 6}$ \\
\hline Precipitation of the Wettest Month & 1.36 \\
\hline Precipitation of the Driest Month & $\mathbf{1 2 . 0 5}$ \\
\hline Precipitation Seasonality & 0.57 \\
\hline Precipitation of the Wettest Quarter & $\mathbf{1 2 . 8 8}$ \\
\hline Precipitation of the Driest Quarter & 1.51 \\
\hline Precipitation of the Warmest Quarter & 0.09 \\
\hline Precipitation of the Coldest Quarter & 0.12 \\
\hline
\end{tabular}

Selective Analysis -- The relative ccontribution of eight ecological variables to the niches of the genus Arenivaga and to 27 species therein. The exploratory analysis showed eight ecological variables contribute $95.24 \%$ to the description of the ecological niche of Arenivaga. Because these eight variables explained such a high percentage of the total niche, they were treated as equally sufficient as all 23 variables for developing ecological niche modeling of Arenivaga and the species included in this study. These variables were soil, ground cover, isothermality, minimum temperature of the coldest month, mean temperature of the driest quarter, annual precipitation, precipitation of the driest month, and precipitation of the wettest quarter. We analyzed the impact of each of these eight variables on the ecological niche of both the genus and the 27 species included in this study. These results are summarized in Figure 5. 


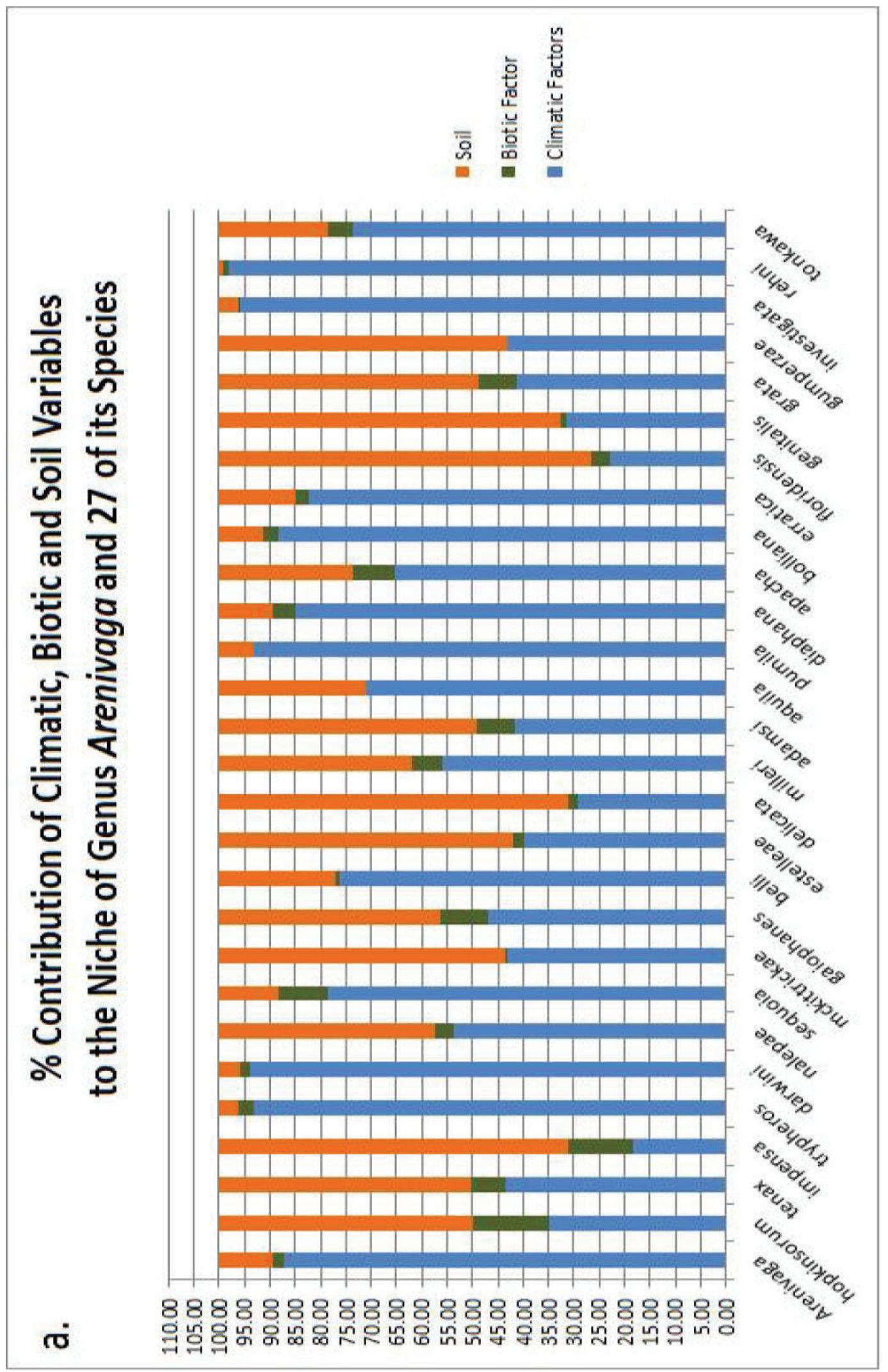




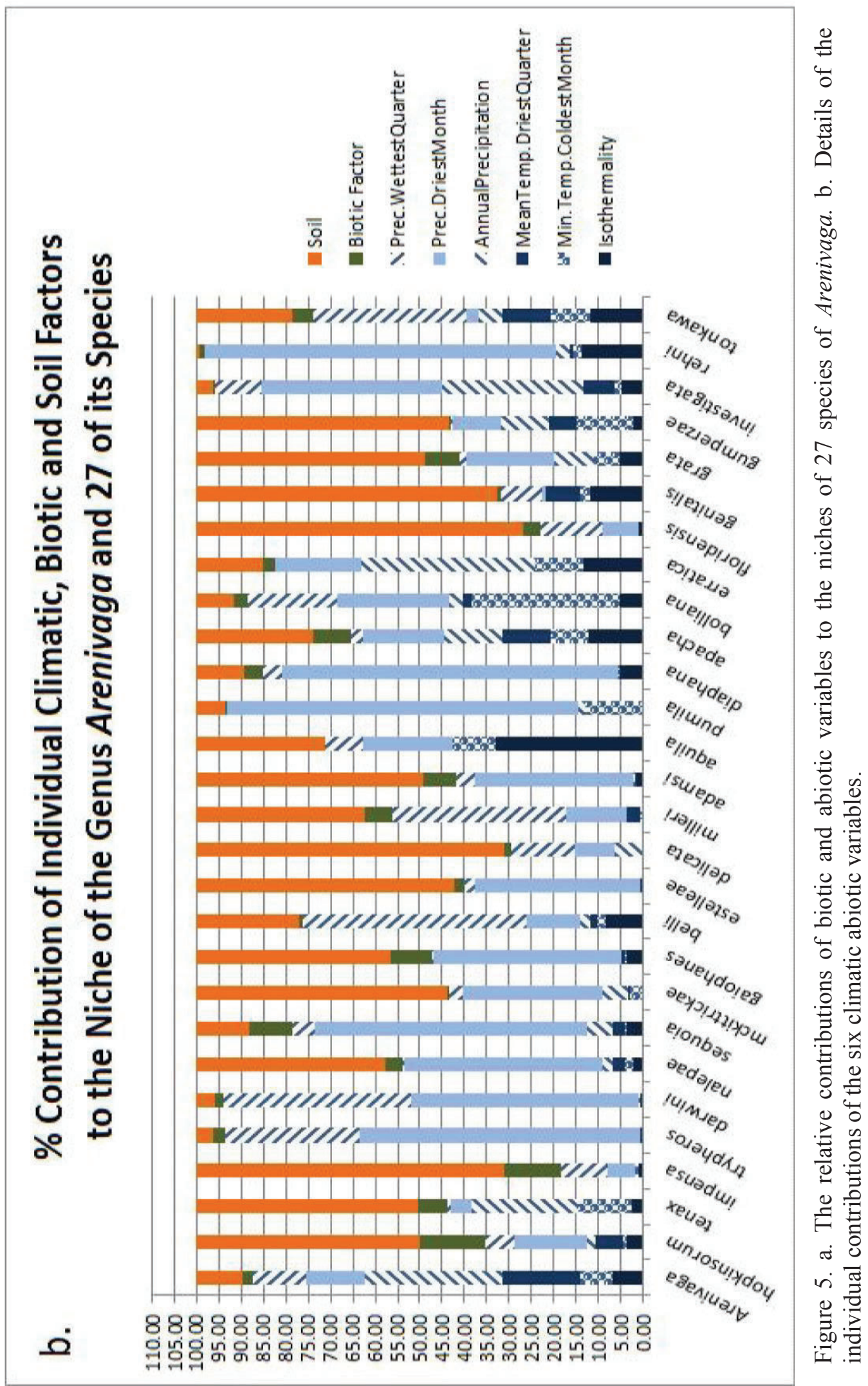


A bootstrap analysis was performed on the presence data to determine the possible impact of small sample size in a minority of included species. The coefficients of variation of the percent importance of variables (either as contribution or permutation) for ten bootstrap replicates were low (CV values for all 27 species mean=0.72 $\mathrm{SD}=0.28$ ) and thus did not suggest an adverse impact of small sample size.

The distributions of the AUCs for training and test data were used as a measure of model performance (Elith et al., 2006). The AUCs for training data from 27 species are 0.88 and above, with a median of 0.98 . The AUCs for test data are 0.77 and above, with a median of 0.97 . While these two groups of data are significantly different $(\mathrm{p}<0.01)$, the scores are all well above 0.5 , indicating the models performed better with the analyzed data than they would with random data.

Cluster and Ordination Analyses. The result of the NMDS analysis is shown in Figure 6 that depicts in two dimensions the relative importance of the eight variables in the selective study. The length and direction of the eight blue arrows indicate the relative strength of each variable overall, and each species name within the matrix is placed proportionately to how each ecological variable impacts its niche. This reveals how alike or unalike Arenivaga species are in their preferred niches overall, those species that are outliers, and which variable(s) cause them to be so. This analysis clearly demonstrates the similarity of the ecological niches of individual species of Arenivaga. It is also evident that A. bolliana, A. aquila, A. apacha and $A$. estelleae are the most extreme outliers of the 27 species analyzed. Arenivaga investigata, A. erratica, A. gumperzae and $A$. tonkawa are somewhat less so. The other 19 species share a more similar ecological niche.

The results in Figure 6 were transformed into a dendrogram showing relatedness of species according to similarity of niche composition (Figure 7a). This dendrogram was compared to the partial phylogeny of the genus shown in Figure $7 \mathrm{~b}$. This comparison revealed that only the sister species A. trypheros and $A$. darwini show a parallel between evolutionary relationship and ecological niche. This result, showing that closely related species occupy terrain that is not alike in composition, would tend to support the proposition that Arenivaga appears to be a highly adaptive group of insects, able to migrate into neighboring habitat that is not identical to the terrain from which they originated. They are adept at niche evolution. 


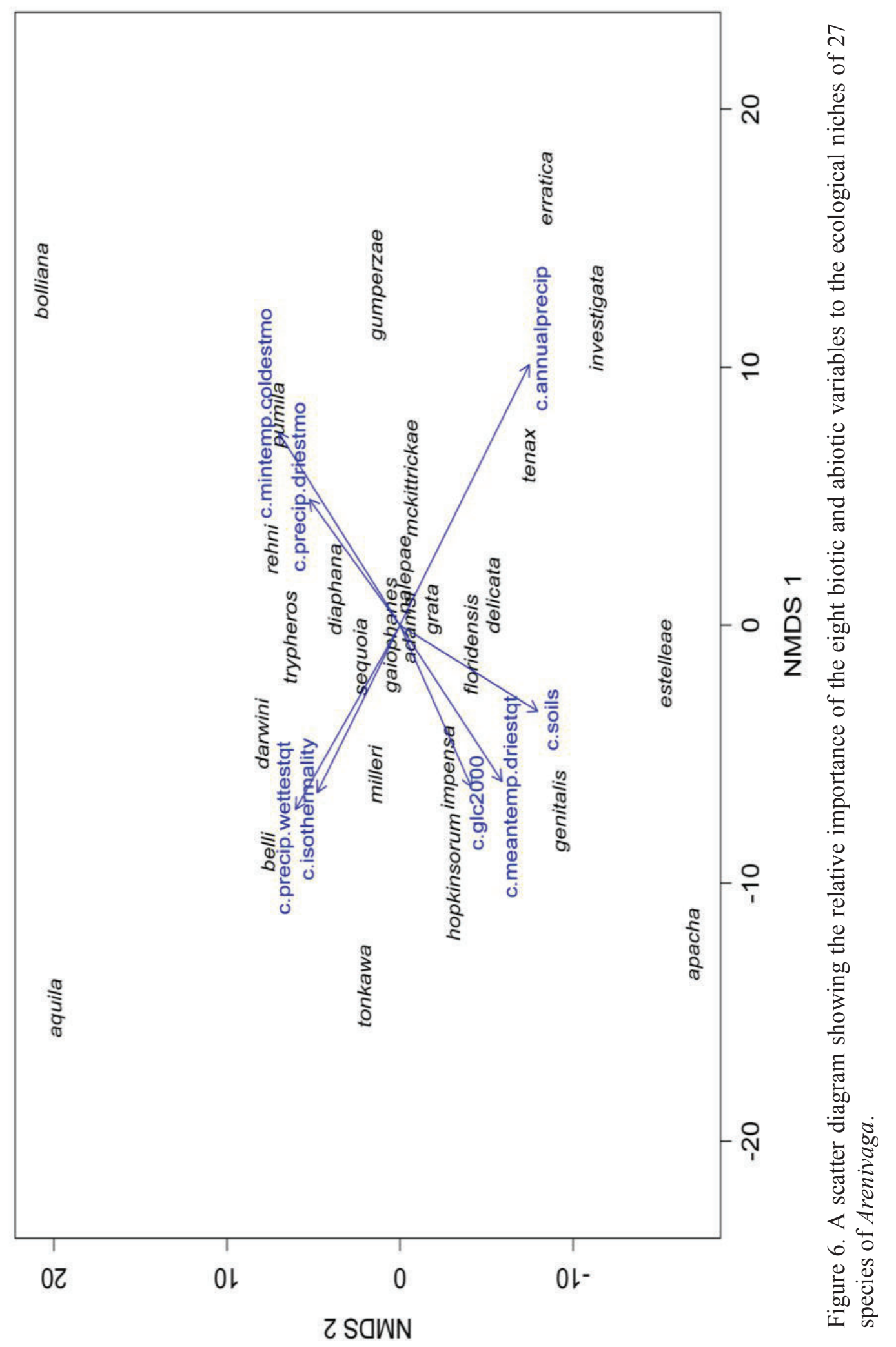


a.

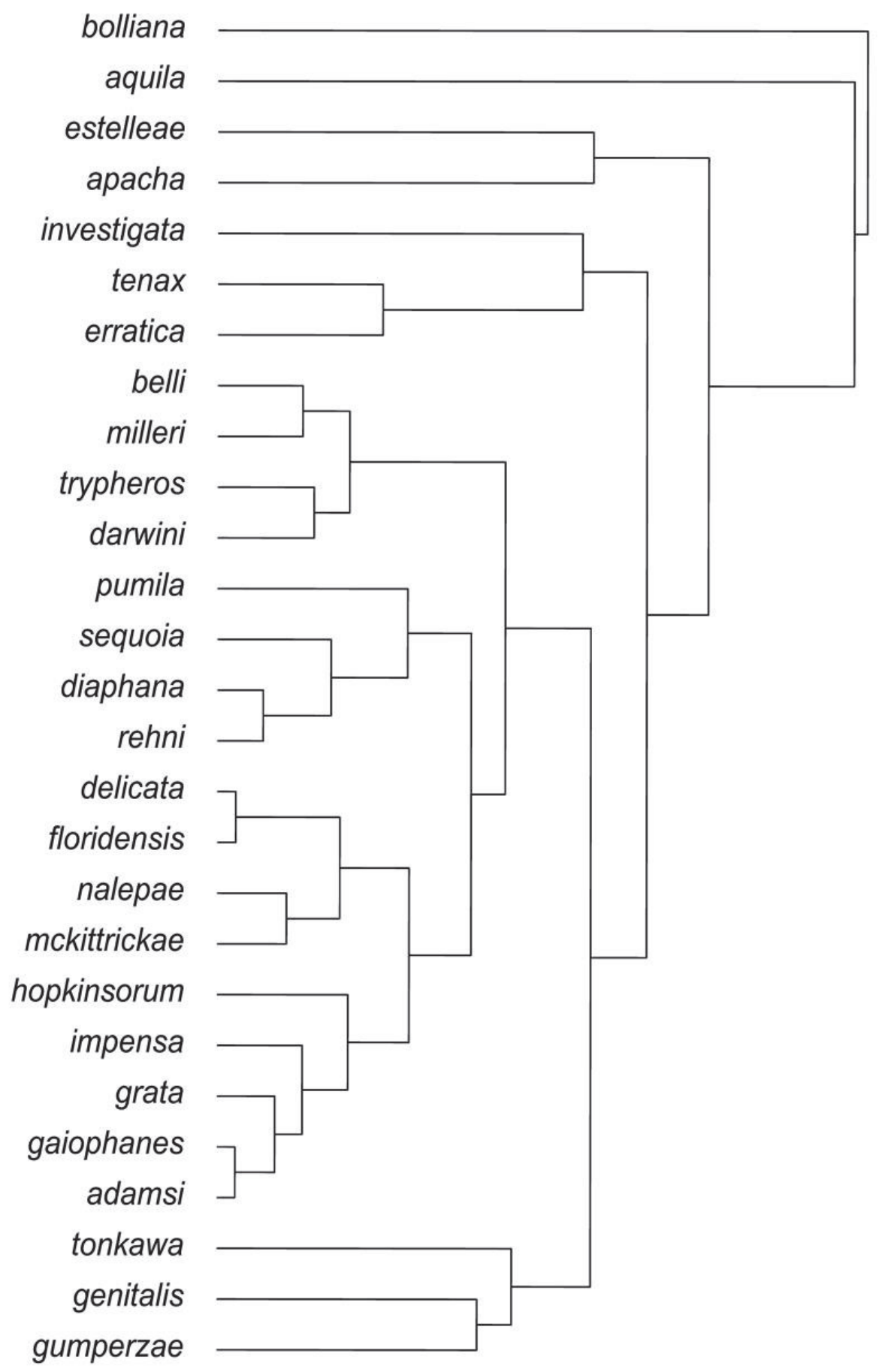

Figure 7. a. A dendrogram of the relative contributions of eight biotic and abiotic ecological variables to the niches of species of Arenivaga as compared to $b$. the Bayesian phylogeny of the genus. Phylogeny created using data from three genes plus morphology; all posterior probabilities of 0.70 or greater are shown. 
b.

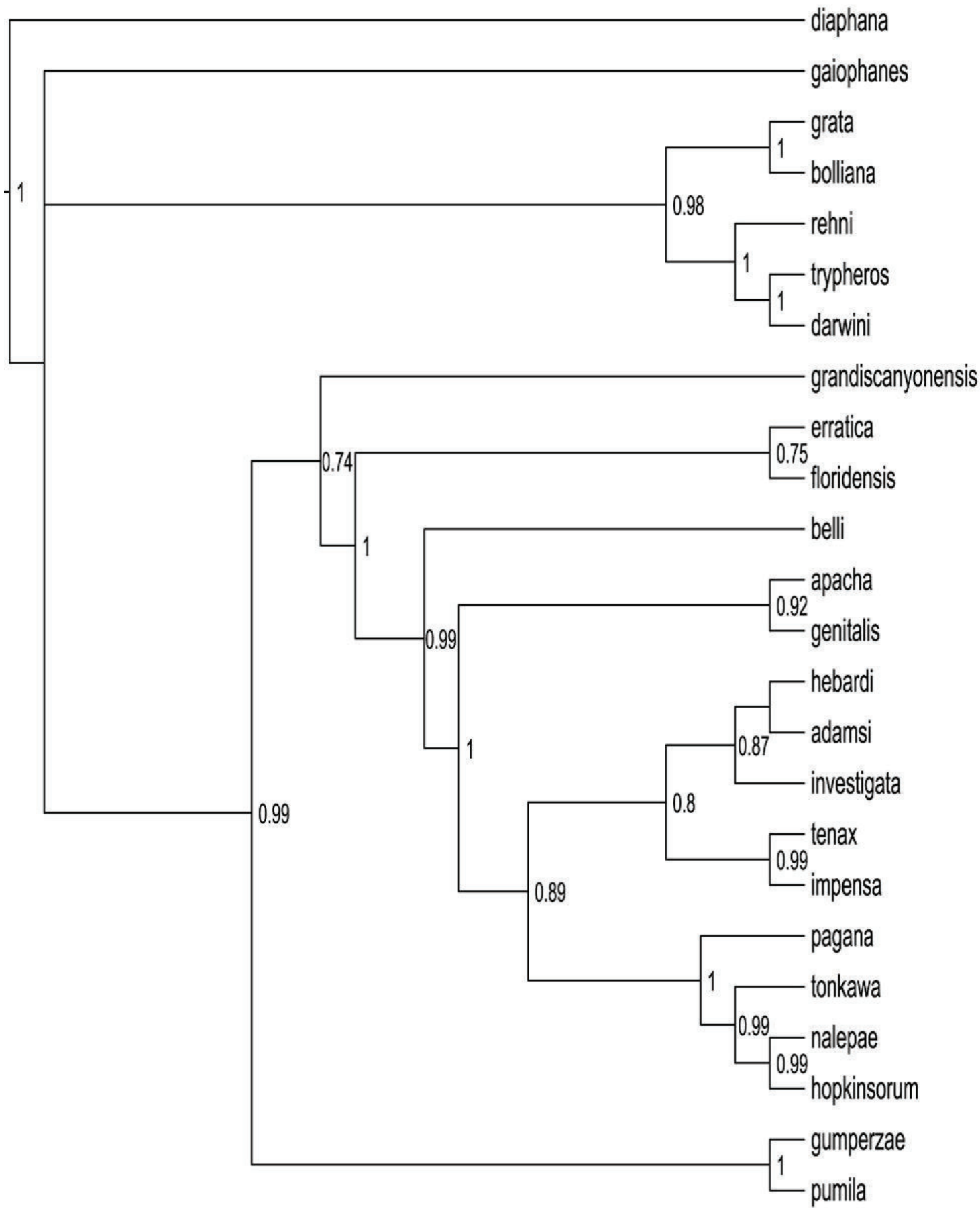




\section{Discussion}

Ecological niche models have been criticized for relying solely on abiotic variables, thereby missing such elements of the realized niche as competition, facilitation or accommodation, and biotic variables such as ground cover or predation (Pearson and Dawson, 2002, and citations therein). Ecological niche models are also unable to account for the roles played by speciation, extinction, dispersal ability, and barriers to dispersal (Pearson and Dawson, 2002; Peterson, 2003; Guisan and Thuiller, 2005; Araujo and Guisan, 2006; Wiens and Donoghue). Despite these limitations, methodology of ENMs is improving (Elith et al., 2006) and such models may be successfully used to discover and quantify parameters that define the habitat of organisms of interest. This information is useful for development of conservation efforts, prediction of a species' possible response to climate change, or delimiting unsurveyed territory in which that species may be found (Gibbons et al., 2011). Here patterns revealed by each of the eight ecological variables that account for more than 95\% of the niche of the genus Arenivaga and 27 of its species are examined, as well as the similarity of niche between species (Figure 3). From this analysis it can be concluded that while the proportion of influence exerted by each variable changes, sometimes considerably, between species of Arenivaga, there is nevertheless discernible consistency between many species.

Soil. A subterranean taxon such as Arenivaga is expected to show considerable preference for certain soil types, and soil does contribute $10 \%$ to the ecological niche of the genus. Figure 5 demonstrates that soil is not just an important abiotic variable in determining species boundaries in this genus; in 11 of the 27 species examined, it contributes $50 \%$ or more to the niche. The species Arenivaga rehni, A. investigata, A. trypheros, and A. darwini appear to have little sensitivity to the soil in their habitats. A closer look at the ranges of $A$. trypheros and A. darwini reveals a topography of sand, rocky buttes, and very sparse flora. Arenivaga investigata occurs over a much larger adjacent acreage, but still one of the driest in the genus and one comprised principally of sand and rock. Perhaps these species must accept any soil type they find in order to find adequate nutrients and/or mates in their harsh habitats. Arenivaga rehni occupies the entirety of the Baja peninsula, which is comprised of many soil types. This species may also be a generalist able adapt to any soil it finds in Baja, the result of which is an inability of this model to discern soil as a major player in the niches of these taxa.

Ground Cover. It is apparent that ground cover, the sole biotic variable in the analysis, plays only a small role in determining the species boundaries of Arenivaga, and contributes less than 5\% to the analyzed niche of the genus as a whole. A pair of species in southern and western Arizona, (A. impensa and $A$. hopkinsorum), show a niche reliance of a little more than $10 \%$ on ground cover. All other species analyzed register a dependence upon ground cover of less than $10 \%$. Such results indicate that for the most part this detritivorous taxon is a 
generalist in its feeding habits and has no habitat restrictions due to type of plant growth. These animals are known to be fungivores, in addition to which pollen has been found in the gut of certain species (Hawke and Farley, 1973; H. Hopkins, pers. obs.) indicating that like most cockroaches, Arenivaga are omnivorous and opportunistic feeders. This is an important discovery in understanding the ecological niche of any taxon since it has been clear to biologists for some time that a taxon's pursuit of nutrients and its position in the food chain are central to its evolutionary ecology (Hutchinson, 1959).

Isothermality. Isothermality contributes less than $10 \%$ to the niche of the genus but is important to the niche of $A$. aquila (32\%) and also to A. apacha, $A$. rehni, A. erratica, A. genitalis, and A. tonkawa. Arenivaga aquila is the species with the smallest sample size in this study, and $A$. rehni, A. erratica, and $A$. tonkawa have large and heterogeneous ranges. Isothermality seems to have an increased impact on a species' niche when studied terrains are either very small (which could be the case with $A$. aquila) or when studied terrains are very large and varied. Arenivaga apacha, which also shows some sensitivity to this variable, is known to cohabit with Neotoma (Cohen and Cohen, 1976); so the $12 \%$ contribution of isothermality to the niche of this species may actually reflect the niche requirements of the facilitating species to which the cockroach has adapted.

Minimum temperature of the coldest month. Arenivaga, as either oothecae or immatures, must overwinter. Many live in places with low winter temperatures. Minimum temperature of the coldest month factors less than $10 \%$ to the genus, but registers $10 \%$ or more in the species A. tenax, A pumila, A. bolliana, A. erratica, and $A$. gumperzae indicating their increased sensitivity to cold. Arenivaga pumila is the smallest of all Arenivaga species and occurs in a restricted range on the Baja peninsula. Their sensitivity to cold may be a function of their small size. Arenivaga bolliana is the largest of all Arenivaga species and is found in the wettest parts of the genus' range in Texas and Florida. A. bolliana's restriction to habitats with higher precipitation levels may indicate that this species is not entirely desert-adapted, and retains the sensitivity to cold of most cockroach species. The possible reasons for cold sensitivity in the other three species is less readily apparent; $A$. erratica is a wide-ranging species across three states and Mexico, A. tenax occurs primarily in New Mexico and far northwestern Texas bordering New Mexico, and A. gumperzae is found in Texas and Mexico.

Mean temperature of the driest quarter. This variable influences the niche of the genus more than $15 \%$, yet contributes only $10 \%$ to the niches of only two studied species, A. apacha and A. tonkawa. Therefore, the significance of this variable to the genus must be found in the 21 species of Arenivaga not included in this study due to inadequate sampling. Previous studies show that $A$. apacha is not well adapted to high temperatures (Cohen and Cohen, 1981); therefore, they may be particularly sensitive to multiple simultaneous 
physiological stressors such as heat (or cold) and lack of moisture. Such studies have not been conducted upon A. tonkawa but its similarity to A. apacha in the niche contribution of this variable may indicate a similar sensitivity.

Annual Precipitation. Annual precipitation contributes the most of all eight variables to the ecological niche of Arenivaga as a genus at just over 30\%. There are species whose ranges are restricted to some of the driest habitat of the genus to which this is also a significant factor (A. tenax, A. erratica, $A$. investigata, and $A$. grata), which is not surprising for a desert species. What is more surprising is how few species report this variable as a major contributor to their niche. Rather precipitation of the driest month and precipitation of the wettest quarter are much more impactful (discussed below).

Precipitation of the driest month. To Arenivaga as a genus, and to 23 of the 27 species analyzed, precipitation of the driest month is a contributing factor of $10 \%$ or more to their ecological niche, contributing as much as $75 \%$ in some instances. Along with soil this is the most widely and strongly contributing variable to the habitats of these species. Since Arenivaga live in some of the driest places on earth (Death Valley, the Mojave Desert, parts of the Baja peninsula), it is expected that their survival would depend on their ability to get through the driest part of the year. An interesting pattern is revealed in this variable in that all the species niches to which it contributes most significantly are found on Baja (A. rehni, A. diaphana, A. pumila), or in far northern Baja and into southeast California (A. darwini, A. trypheros). The group impacted just slightly less than these occur just north of the first group, in the central California valley and Mojave desert (A. investigata, A. nalepae, A. sequoia, A. gaiophanes, A. estelleae, A. mckittrickae) and in Mexico along the eastern side of the Gulf of California (A. adamsi). This very likely reflects the amount of precipitation in the driest month in those two geographic areas, and the speciation that has taken place in Arenivaga may also reflect the adaptive ability to this ecological variable. It is worth noting those species that show little to no dependence on this variable, (A. tonkawa, A. genitalis, A. impensa, and A. tenax) because one or more of these has shown a similar lack of dependence on others of the eight variables (soil, annual precipitation, mean temperature of the driest quarter, ground cover and isothermality).

Precipitation of the wettest quarter. It is believed that the peak of Arenivaga breeding season is during the warmest quarter of the year, and that successful reproductive efforts require adequate precipitation to prevent dessication of oothecae and dehydration of fragile first instars. Over much of the habitat of Arenivaga the warmest quarter is also the wettest quarter. This translates into abundant nutrients for the rapid growth of immatures and fat storage for overwintering. This ecological variable is the third most important overall, and contributes $10 \%$ or more to the niches of the genus and to ten of the included species. There is some geographic cohesion among these species: several for which this variable is important occur in southern and central 
California (A. trypheros, A. darwini, A. belli, A. delicata, A. milleri) and another pair occur in Texas (A. tonkawa, A. bolliana). These two groups occur in quite diverse habitats; therefore, these results may indicate that the wettest quarter of the year occurs at different times of year and has a different set of impacts between the two groups.

Niche overlap within 27 Species of Arenivaga. This examination of the distribution of species across the landscape according to the relative contributions of niche variables (Figure 6) revealed that most Arenivaga species have niches that are overlapping in their makeup. This is demonstrated by the concentration of species names around the center point of Figure 6 . The lack of congruence between a dendrogram of species niche composition and the phylogeny of the genus (Figure 7) confirms that sister species do not share identical niches but rather occupy a neighboring terrain that has some measurable difference in one or more ecological factors (Hoffman and Blows, 1994; Zink, 2013). The role of ecology in speciation is well-documented (Hoffman and Blows, 1994; Schluter, 2000; Wiens and Graham, 2005; Butlin et al., 2012). Arenivaga species are impacted by a limited set of ecological variables (Table 1) but the relative contributions of those variables to the niche of each species is distinctly, if often narrowly, different (Figure 5). Sometimes those niches are remarkably similar in their composition (A. floridensis and $A$. delicata, A. hopkinsorum and A. grata, A. nalepae and A. gaiophanes, $A$. mckittickae and $A$. estelleae, $A$. rehni and $A$. pumila) but the species with such similar niches are neither closely related nor adjacent geographically. An exception to this pattern is $A$. trypheros and $A$. darwini which have parapatric distibutions with a considerable area of overlap, very similar niche composition, and are sister species. There are only fine distinctions between their habitats though this may be enough to create reproductive isolation between the two species (Zink, 2013). This curious pair of species continues to generate questions (Hopkins, 2014)

In contrast to the above are those species of Arenivaga that have unique ecological niches. These are indicated in Figure 6 by their position far from the center point, and in most instances equally far from any other species: $A$. bolliana, A. apacha, A. aquila, and A. estelleae. Arenivaga bolliana occurs in habitat with high precipitation relative to all other species except $A$. floridensis. It also lacks the unusual wing brace character that is thought to be required for successful subterranean movement by adult males (Hopkins, 2014). This species may be one of the least desert-adapted of the Arenivaga, and this fact may be demonstrated by their very divergent and unique ecological niche. Arenivaga apacha is the only species of Arenivaga known to cohabit with a desert mammal, and this has been shown to ameliorate their niche greatly (Cohen and Cohen, 1981). Their niche composition reflects this facilitated relationship. Arenivaga aquila and A. estelleae are new species recently described (Hopkins, 2014). Their unusual niche composition when compared to the rest of the genus 
makes them interesting subjects for future study. It is not known whether one or both of these species also cohabits with a desert mammal.

\section{Conclusion}

These analyses reveal that eight out of 23 ecological variables contribute more than $95 \%$ to the niche of Arenivaga. When these eight variables were used to examine the niches of individual species, three variables stood out as dominant in the niches of many species: soil, precipitation of the driest month, and precipitation of the wettest quarter. The genus is fossorial, mostly desertdwelling, detritivorous, extremophiles, and it was anticipated that soil, precipitation, and ground cover (as a proxy for food) would be important to their environment. Soil is the most significant, and the most universally important ecological factor to niche composition. Precipitation of the driest month is also highly significant and nearly universal in its importance. Precipitation of the wettest quarter is of slightly less significance and not as widely important. Ground cover did not prove to be an important contributor to the niches of the 27 species studied.

The adaptive abilities of Arenivaga in a heating, drying planet are evidenced by the radiation of the genus across Mexico, Baja and the American Southwest. The geologic history of the land encompassed by Arenivaga's distribution is complex. Much of the American Southwest and portions of northern Mexico have been subject to regional uplift and orogenesis, extensive volcanism, and erosion over the past 45 million years that have resulted in the complex basin and range, plateau and trough, mountain and canyon topography that we see today (http://semken.asu.edu/teaching/GeolHistSw.pdf, and citations therein). The San Andreas fault which opened up the proto Bay of California and originated the Baja peninsula began its work only 15 million years ago (Kumar, 2013). Both the Baja Peninsula and the American Southwest are heterogeneous in their topography, flora, and weather regimes that have led to high levels of endemism and diversity (Hopkins, 2014; Kumar, 2013; McLaughlin, 1986; 1989; Calsbeek et al., 2003). In addition to the geologic forces upon the landscape, alternating wet and dry periods, and more recently cold and hot oscillations, have resulted in present day deserts interspersed with mountains, canyons, relic watersheds, playas, alluvial fans, eolian dune fields, as well as plant-stabilized dunes, (http://pubs.usgs.gov/of/2004/1007/geologic.html, and citations therein) all of which are inhabited by Arenivaga.

Given the geologic history of the land they inhabit, it is not surprising that soil, precipitation of the driest month, and precipitation of the wettest quarter are the three most influential ecological factors in the niches of many species in this group today. These are the elements with which the niche of Arenivaga may be described as conserved. It is also not surprising that they have spread to occupy such a large expanse. They currently inhabit a world that is hot and dry, and have sought refuge from the elements in the soil. It would be easy to label this a 
genus of extremophiles with known physiological adaptations for life in the harshest deserts, and there are species for which this description would be accurate. However, it is also true that Arenivaga has exploited the varied climate regimes and other vicariant events over its evolutionary history in an extraordinarily successful manner, as indicated by its wide-ranging distribution, and the surprising variety of ecological niches it occupies as revealed in this analysis. A recent survey of $A$. floridensis reveals that this species has expanded into the broadest habitat of any Florida sand ridge endemic (Lamb et al., 2006). Arenivaga do not only occur in deserts, they are not only found in sand dunes, they show almost no dependence on ground cover, and while not cohabiting with humans, they apparently are not sensitive to anthropogenic impacts (H.Hopkins, R.Rice, K.Wright, R.Thornhill, personal observation).

Wiens and Donoghue (2004) observe that the interplay between niche conservatism and niche evolution $t$ is a major theme in the exploration of the biogeography of a clade. They point out that ENMs may answer the 'how many' question of species occurrence in present-day conditions. However, combining what we learn from ENMs with historical geology and vicariant biogeography can answer additional "who did what, where, when and why", thereby incorporating the forces of speciation, dispersal and extinction into biogeographic analyses (e.g. Smith et al., 2005). Arenivaga would be a fruitful subject of such research and this paper takes a first step. While Arenivaga appears to readily adapt to the vagaries of most of the abiotic conditions tested, it is at the same time considerably sensitive to soil composition and precipitation in the driest month, and relatively impervious to ground cover. There are species of Arenivaga whose niche composition is strikingly divergent from the majority of species. Are these species basal or recently derived within the genus? Do any of them cohabit with members of another phylum? Are their lives less subterranean than other species? How desert-adapted are they? How stenotopic are they? These cryptic animals are a source of many further intriguing questions about adaptation and speciation and may have much to teach us about how to survive and thrive.

\section{Acknowledgements}

I, Heidi Hopkins, wish to acknowledge and thank my dissertation advisor, Dr. Kelly Miller, Curator of Arthropods at the Museum of Southwestern Biology, and Associate Professor at University of New Mexico. I would also like to thank my dissertation committee, Dr. Timothy Lowrey, Dr. Christopher Witt, and Dr. Jessica Ware, for their close reading of my efforts and suggestions for improvement. Many, many thanks go to Lorraine McInnes for all the ArcGIS lessons and help. My collaborator, Dr. Tomas Giermakowski, has been a pleasure to work with. I am also particularly grateful to all the institutions and individuals that loaned specimens. My work has been supported by grants from AMNH (Roosevelt Grant), ANSP (Jessup Fellowship), and USNM (Shortterm Visitor Grant). I also received support from the Office of Graduate Studies at UNM (RPT Grant). I thank all these funding sources for their generous support. 


\section{Literature Cited}

Appel, A. G., A. M. Van Dyke, and M. K. Rust. 1983. A technique for rearing and some notes on the biology of a Desert Sand Cockroach Arenivaga investigata (Dictyoptera: Polyphagidae). Proceedings of the Entomological Society of Washington 85:598-600.

Araujo, M. B. and A. Guisan. 2006. Five (or so) challenges for species distribution modelling. Journal of Biogeography 33:1677-1688. http://dx.doi.org/10.1111/j.1365-2699.2006.01584.x

Araujo, M. B. and M. Luoto. 2007. The importance of biotic interaction for modelling species distributions under climate change. Global Ecology and Biogeography 16:743-753. http://dx.doi.org/10.1111/j.1466-8238.2007.00359.x

Busby, J. R. 1991. BIOCLIM - A Bioclimatic Analysis and Prediction System. pp. 64-68. In, Margules, C. R. and M. P. Austin (Editors). Nature Conservation: Cost Effective Biological Surveys and Data Analysis. CSIRO, Canberra. 207 pp.

Butlin, R., J. Bridle, and D. Schluter. (Editors). 2012. Speciation and Patterns of Diversity. Cambridge University Press. Cambridge, England, UK. 333 pp.

Calsbeek, R., J. N. Thompson, and J. E. Richardson. 2003. Patterns of molecular evolution and diversification in a biodiversity hotspot: the California Floristic Province. Molecular Ecology 12:1021-1029. http://dx.doi.org/10.1046/j.1365-294X.2003.01794.x

Cohen, A. C. and J. L. Cohen. 1976. Nest structure and micro-climate of the Desert Cockroach, Arenivaga apacha (Polyphagidae, Dictyoptera). Bulletin of the Southern California Academy of Sciences 75:273-277.

Cohen, A .C. and J. L. Cohen. 1981. Microclimate, temperature and water Relations of two species of desert cockroaches. Comparative Biochemical Physiology 69A:165-167. doi: 10.1016/03009629(81)90656-3.

Coope, G. R. 1994. The response of insect faunas to glacial-interglacial climatic fluctuations. Philosophical Transactions: Biological Sciences 344(1307):19-26. http://dx.doi.org/10.1098/rstb.1994.0046

Edney, E. B. 1968. The effect of water loss on the haemolymph of Arenivaga sp. and Periplaneta americana. Comparative Biochemical Physiology 25:149-158. doi: 10.1016/0010406X(68)90921-3.

Edney, E. B., P. Franco, and R. Wood. 1978. The reponses of Arenivaga investigata (Dictyoptera) to gradients of temperature and humidity in sand studies by tagging with Technetium $99 \mathrm{~m}$. Physiological Zoology 51:241-255.

Edney, E. B., S. Haynes, and D. Gibo. 1974. Distribution and activity of the Desert Cockroach Arenivaga investigata (Polyphagidae) in relation to microclimate. Ecology 55:420-427. doi: $10.2307 / 1935230$.

Edney, E.B. and J. McFarlane. 1974. The Effect of Temperature on Transpiration in the Desert Burrowing Cockroach, Arenivaga investigata and in Periplaneta americana. Physiological Zoology 47:1-12.

Elith, J., M. Kearney, and S. Phillips. 2010. The art of modelling range-shifting species. Methods in Ecology and Evolution 1:330-342. http://dx.doi.org/10.1111/j.2041-210X.2010.00036.x

Elith, J., C. H. Graham, R. P. Anderson, M. Dudík, S. Ferrier, A. Guisan, R. J. Hijmans, F. Huettmann, J. R. Leathwick, A. Lehmann, J. Li, L. G. Lohmann, B. A. Loiselle, G. Manion, C. Moritz, M. Nakamura, Y. Nakazawa, J. McC. M. Overton, A. Townsend Peterson, S. J. Phillips, K. Richardson, R. Scachetti-Pereira, R. E. Schapire, J. Soberón, S. Williams, M. S. Wisz, and N, E. Zimmermann. 2006. Novel methods improve prediction of species' distributions from occurrence data. Ecography 29:129-151. http://dx.doi.org/10.1111/j.2006.0906-7590.04596.x

Elith, J. and J. R. Leathwick. 2009. Species distribution models: Ecological explanation and prediction across space and time. Annual Review of Ecology Evolution and Systematics 40:677697. http://dx.doi.org/10.1146/annurev.ecolsys.110308.120159

Gaston, K. J. 1998. Species-Range Distributions: Products of speciation, extinction and transformation. Philosophical Transactions: Biological Sciences 353(1366):219-230. http://dx.doi.org/10.1098/rstb.1998.0204

Gibbons, R. E., J. Barrio, G. A. Bravo, and L. Alza. 2011. Assessing the geographic range of Black- 
fronted Ground-Tyrants (Muscisaxicola frontalis) using extralimital and winter range occurrence records and ecological niche modeling. Journal of Field Ornithology 82(4):355365. doi: 10.1111/j.1557-9263.2011.00339.x.

Goslee, S. C. and D. L. Urban. 2007. The ecodist package for dissimilarity-based analysis of ecological data. Journal of Statistical Software 22(7):1-19.

Guisan, A., and W. Thuiller. 2005. Predicting species distribution: offering more than simple habitat models. Ecology Letters 8:993-1009. http://dx.doi.org/10.1111/j.1461-0248.2005.00792.x

Hartman, H. B., L. P. Bennett, and B. A. Moulton. 1987. Anatomy of rquilibrium receptors and cerci of the Burrowing Desert Cockroach Arenivaga (Insecta, Blattodea). Zoomorphology 107:8187. doi: $10.1007 / \mathrm{BF} 00312117$.

Hawke, S. D. and Farley, R. D. 1971a. Antennal chemoreceptors of the Desert Burrowing Cockroach, Arenivaga sp. Tissue and Cell 3:649-664. doi: 10.1016/S0040-8166(71)80011-3.

Hawke, S. D. and Farley, R. D. 1971b. The role of pore structures in the selective permeability of antennal sensilla of the Desert Burrowing Cockroach, Arenivaga sp. Tissue and Cell 3:665674. doi: 10.1016/S0040-8166(71)80012-5.

Hawke, S.D. and Farley, R.D. 1973. Ecology and Behavior of the Desert Burrowing Cockroach, Arenivaga sp. (Dictyoptera, Polyphagidae). Oecologia 11:263-279. doi: 10.1007/BF01882784.

Hijmans, R. J., S. E. Cameron, J. L. Parra, P. G. Jones, and A. Jarvis. 2005. Very high resolution interpolated climate surfaces for global land areas. International Journal of Climatology 25:1965-1978. http://dx.doi.org/10.1002/joc.1276

Hobson, R. D. 1972. Surface roughness in topography: quantitative approach. pp. 221-245. In, R. J. Chorley (Editor). Spatial analysis in geomorphology. Harper and Row. New York, NY, USA. 393 pp.

Hoffman, A. A. and M. W. Blows. 1994. Species borders: ecological and evolutionary perspectives. Trends in Ecology and Evolution 9(6):223-227. http://dx.doi.org/10.1016/01695347(94)90248-8

Hopkins, H. 2014. A revision of the genus Arenivaga (Rehn) (Blattodea, Corydiidae), with descriptions of new species and key to the males of the genus. ZooKeys 384:1-256. doi: 10.3897/zookeys.384.6197

Hutchinson, G. E. 1959. Homage to Santa Rosalia or Why are there so many types of animals? The American Naturalist 93(870):145-159. http://dx.doi.org/10.1086/282070

Jackson, L. L. 1983. Epicuticular lipid composition of the Sand Cockroach, Arenivaga investigata. Comparative Biochemical Physiology 74B:225-257.

James, G., D. Witten, T. Hastie, T. and R. Tibshirani. 2013. An Introduction to Statistical Learning with Applications in R. Springer, New York. 426 pp. http://dx.doi.org/10.1007/978-1-46147138-7

Kumar, A. 2013. Geological history of the Baja California Peninsula, Mexico and the fascinating world of its endemic plants. Earth Science India 6(3):1-27. http://dx.doi.org/10.1017/9789382993308.002

Lamb, T., Justice, T.C., and Justice, M. 2006. Distribution and status of the Cockroach Arenivaga floridensis Caudell, a Florida Sand Ridge Endemic. Southeastern Naturalist 5(4):587-598. http://dx.doi.org/10.1656/1528-7092(2006)5[587:DASOTC]2.0.CO;2

Latifovic, R., Z. L. Zhu, J. Cihlar, J. Beaubien, and R. Fraser. 2003. The land cover map for North America in the year 2000. GLC2000 database, European Commission Joint Research Centre. Available at http://www-gem.jrc.it/glc2000 [accessed October 2013].

Latifovic, R., Z. L. Zhu, J. Cihlar, and I. Olthof. 2004. Land cover mapping of North America, Global Land Cover 2000. Remote Sensing of Environment 89(1):116-127. doi: 10.1016/ j.rse.2003.11.002

Lomolino, M., J. H. Brown, and B. Riddle. 2005. Biogeography. Sinauer Associates. Sunderland, Massachusetts, USA. 875 pp.

MacKenzie, D. I., J. D. Nichols, G. B. Lachman, S, Droege, J. A. Royle, and C. A. Langtimm. 2002. Estimating site occupancy rates when detection probabilities are less than one. Ecology 83:2248-2255. http://dx.doi.org/10.1890/0012-9658(2002)083[2248:ESORWD]2.0.CO;2

McLaughlin, S. P. 1986. Floristic analysis of the southwestern United States. Great Basin Naturalist 
46:46-65.

McLaughlin, S. P. 1989. Natural floristic areas of the Western United States. Journal of Biogeography 16(3):239-248. http://dx.doi.org/10.2307/2845260

Nachtergaele, F. O., van Velthuizen, H., L. Verelst, D. Wiberg, N. H. Batjes, J, A, Dijkshoorn, V. W. P. van Engelen, G. Fischer, A. Jones, L. Montanarella, M. Petri, S. Prieler, E Teixeira, and X. Shi. 2012. Harmonized World Soil Database (version 1.2). Food and Agriculture Organization of the UN, International Institute for Applied Systems Analysis, ISRIC - World Soil Information, Institute of Soil Science - Chinese Academy of Sciences, Joint Research Centre of the EC (FAO/IIASA/ISRIC/ISSCAS/JRC). FAO, Rome, Italy and IIASA, Laxenburg, Austria.

O’Donnell, M.J. 1977. Site of water vapour absorption in the Desert Cockroach, Arenivaga investigata. Proceedings of the National Academy of Sciences of the USA 4:1757-1760. doi:10.1073/pnas.74.4.1757.

O'Donnell, M. J. 1981. Fluid movements during water-vapor absorption by the Desert Burrowing Cockroach, Arenivaga investigata. Journal of Insect Physiology 27:877-887. doi: 10.1016/0022-1910(81)90089-5.

O’Donnell, M. J. 1982. Hydrophilic Cuticle - The basis for water vapour absorption by the Desert Burrowing Cockroach, Arenivaga investigata. Journal of Experimental Biology 99:43-60.

Pearson, R. G. and T. P. Dawson. 2003. Predicting the impacts of climate change on the distribution of species: are bioclimate envelope models useful? Global Ecology and Biogeography 12:361371. http://dx.doi.org/10.1046/j.1466-822X.2003.00042.x

Peterson, A. T. and K. P. Cohoon. 1999. Sensitivity of distributional prediction algorithms to geographic data completeness. Ecological Modelling 117:159-164. http://dx.doi.org/10.1016/S0304-3800(99)00023-X

Peterson, A. T. 2003. Predicting the geography of species' invasions via ecological niche modeling. The Quarterly Review of Biology 78(4):419-433. http://dx.doi.org/10.1086/378926

Phillips, S. J., R. P. Anderson, and R. E. Schapire. 2006. Maximum entropy modeling of species geographic distributions. Ecological Modelling 190:231-259. http://dx.doi.org/10.1016/j.ecolmodel.2005.03.026

Phillips, S. J., and M. Dudík. 2008. Modeling of species distributions with Maxent: new extensions and a comprehensive evaluation. Ecography 31:161-175. http://dx.doi.org/10.1111/j.09067590.2008.5203.x

R Core Team. 2013. R: A language and environment for statistical computing. R Foundation for Statistical Computing. Vienna, Austria. URL http://www.R-project.org/.

Sappington, J. M., K. M. Longshore, and D. B. Thomson. 2007. Quantifiying landscape ruggedness for animal habitat anaysis: a case study using Bighorn Sheep in the Mojave Desert. Journal of Wildlife Management 71(5):1419 -1426. http://dx.doi.org/10.2193/2005-723

Schluter, D. 2000. The Ecology of Adaptive Radiation. Oxford University Press. Oxford, England, UK. 288 pp.

Smith, S. A., P. R. Stephens, and J. J. Wiens. 2005. Replicate patterns of species richness, historical biogeography, and phylogeny in Holarctic treefrogs. Evolution 59(11):2433-2450. http://dx.doi.org/10.1111/j.0014-3820.2005.tb00953.x

VanDerWal, J., L. P. Shoo, C. Graham, and S. E. Williams. 2009. Selecting pseudo-absence data for presence-only distribution modeling: How far should you stray from what you know? Ecological Modelling 220:589-594. http://dx.doi.org/10.1016/j.ecolmodel.2008.11.010

Walthall, W. W. and H. Bernard Hartman. 1981. Receptors and Giant Interneurons Signaling Gravity Orientation Information in the Cockroach Arenivaga. Journal of Comparative Physiology A 142:359-369. http://dx.doi.org/10.1007/BF00605448

Warren, D. L., R. E. Glor, and M. Turelli. 2010. ENMTools: a toolbox for comparative studies of environmental niche models. Ecography 33:607-611.

Wiens, J. J. and M. J. Donoghue. 2004. Historical biogeography, ecology and species richness. Trends in Ecology and Evolution 19(12):639-644. http://dx.doi.org/10.1016/j.tree.2004.09.011

Wiens, J. J. and C. H. Graham. 2005. Niche Conservatism: Integrating evolution, ecology, and conservation biology. Annual Review of Ecological and Evolutionary Systematics 36:519-539. 
http://dx.doi.org/10.1146/annurev.ecolsys.36.102803.095431

William, W. W. and H. H. Bernard. 1981. Receptors and giant interneurons signaling gravity orientation information in the cockroach Arenivaga. Journal of Comparative Physiology A 142:359-369. doi: 10.1007/BF00605448.

Zink, R. M. 2013. Homage to Hutchinson, and the role of ecology in lineage divergence and speciation. Journal of Biogeography 41(5):999-1006. doi: 10.1111/jbi.12252.

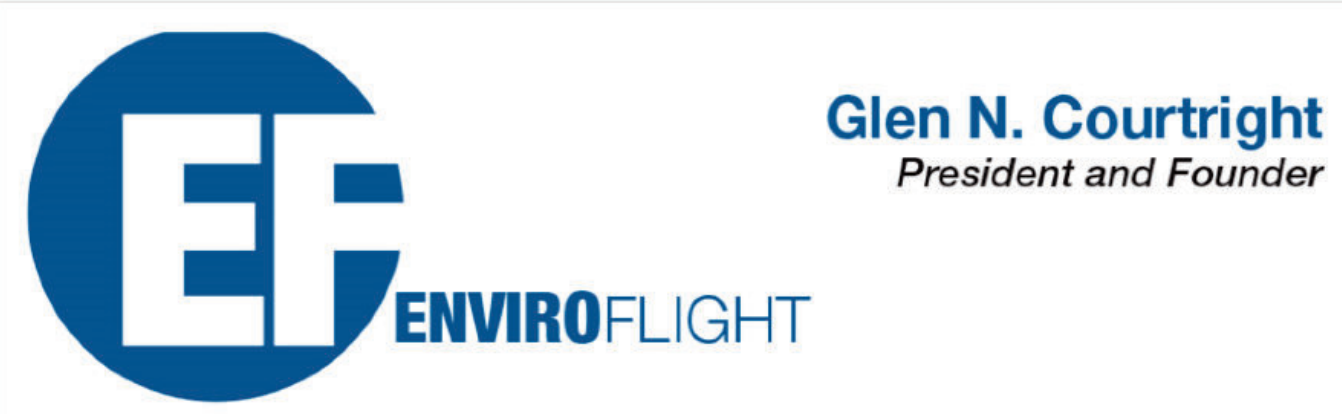

303 North Walnut Street

Yellow Springs, OH 45387

Direct: (937) 367-2938

Office: (937) 767-1988

Fax: (937) 767-1488 glen@enviroflight.net

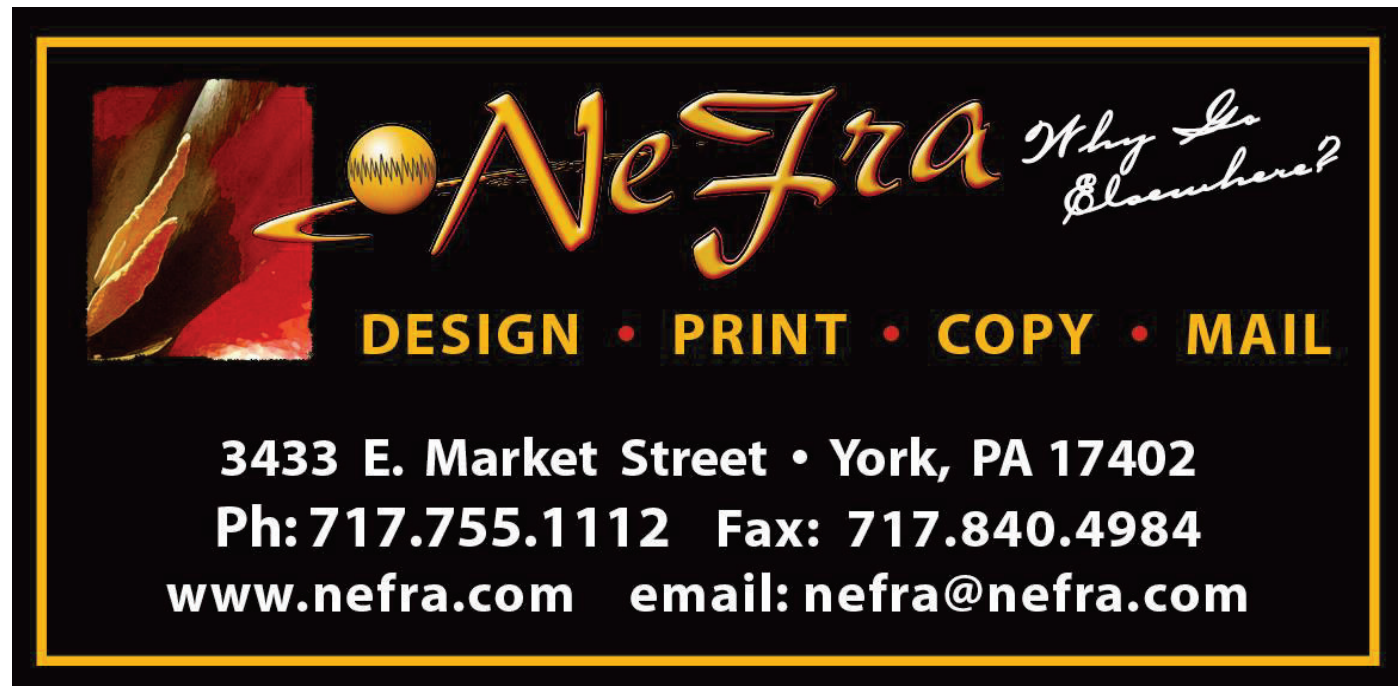

